\title{
EFFECTS OF GROUND MOTIONS ON AMPLITUDE INTERFEROMETRY
}

Peter L. Bender*

Joint Institute for Laboratory Astrophysics, Boulder, Colorado 80309

\section{ABSTRACT}

Some examples are given of types of ground motion which he.ve been observed with seismic and geodetic instruments. In general, away from sources of man-made noise, the amplitudes of ground strains and tilts in the microseism band with periods of a few seconds normally are of the order of a few times $10^{-10}$ Strain and tilt tides give amplitudes of a few times $10^{-8}$, and long term average strain and tilt rates at relatively good sites may be roughly $10^{-7} / \mathrm{yr}$. Superposed on such relatively long wavelength motions can be larger local pier motions, which are likely to be irregular. However, very high ground stability has been demonstrated at a few sites The limitations of ground motions on long term amplitude interferometer stability are serious if applications such as earth rotation and polar motion measurements are considered, but at shorter periods the environmental problems will be almost completely atmospheric.

\section{INTRODUCTION}

The purpose of this paper is to give some examples of types of ground motions which might be considered in thinking about the design of stellar interferometers. Preparation of the paper did not include a careful search of the literature. More complete references undoubtedly exist for some of the phenomena discussed, such as microseisms and long period seismic waves. However, it is hoped that the examples given will be useful in indicating some of the phenomena of interest. Crustal movements in active tectonic areas or in subsidence areas will not be covered.

Staff Member, Quantum Physics Division, National Bureau of Standards, and Department of Physics and Astrophysics, University of Colorado. 


\section{SHORT PERIOD GROUND MOTIONS}

Ground motions with periods of much less than $1 \mathrm{sec}$ are not likely to be important except at the time of earthquakes. However, motions with periods of the order of $1-10 \mathrm{sec}$ can be significant. These so-called microseisms often have a peak in their spectrum for a period of about $6 \mathrm{sec}$. At some times at locations near the oceans, a lower frequency band with periods of 1 or $2 \mathrm{sec}$ may be present also. Much of the microseism power is belleved to be due to waves in the oceans during storms which cause pressure waves on the ocean floor These waves can be transmitted through the earth and generally give maximum microseism amplitudes near the coasts.

As an example, some amplitudes of microseisms recorded at Berkeley, California during nearby storms are given in a paper by Latham and Nowroozi. ${ }^{1}$ The amplitudes observed were of the order of 1 or 2 microns peak to peak. At the same time, ocean bottom seismographs operating some distance offshore gave amplitudes of 5 or 10 microns peak to peak. Since the wavelengths in the main microseism band are about $20 \mathrm{~km}$, the rms tilts and strains corresponding to an rms ground motion of 1 micron are only a few times $10^{-10}$. Such small motions are likely to be negligible compared with the effects of atmospheric refraction changes.

Ground motions with periods of the order of $10-100 \mathrm{sec}$ are generally substantially lower in amplitude. For example, observations made with long period seismographs at 6 world-wide locations are described by Murphy, et $a 1 .{ }^{2}$ The power spectra of the ground motions observed at the different sites are surprisingly similar and have a spectral density for vertical motions of less than $0.1 \mu^{2}$ per $\mathrm{Hz}$ over this entire period range.

Going to longer periods, the next phenomena of interest are free oscillations of the earth. These can be excited by large earthquakes and have been observed with both gravimeters and strainmeters. The lowest frequency normal mode has a period of $55 \mathrm{~min}$, and a large number of higher frequency modes with periods down to a few minutes also have been observed. The total amplitude of ground motion after a magnitude 7-1/2 or 8 earthquake can be several tens of centimeters and the $Q$ of the modes is high enough so that the 
ground motions can be observed for periods of a week or more. However, the long wavelengths of the most highly excited modes means that the amplitudes in strain and tilt will be only on the order of a few times $10^{-8}$.

\section{PERIODS OF HOURS TO DAYS}

Tidal tilts and strains in the solid earth have amplitudes of a few times $10^{-8}$ in the semi-diurnal and diurnal bands. The solid earth tide part can be calculated quite accurately from present knowledge of the Love numbers for the earth and the disturbing potential. However, ground distortions due to loading of the earth by the ocean tides also can be substantial. The ocean tides are not very well known at present and have substantial power at relatively high degree spatial harmonics. Particularly near the coasts the effects on strain and tilt can be substantial. However, with improving knowledge of the ocean tides and with modeling of the effects of the local tides in the nearby parts of the ocean, the tidal effects should not be a continuing problem at the $10^{-8}$ level for most locations.

For periods of a day or two one interesting type of tilt disturbance which has been observed is due to storm surges in the North Sea. As an example, Zschau ${ }^{3}$ has reported observing a surface tilt of about $1.5 \times 10^{-7}$ radians at a distance of 70 kilometers from the North Sea coast during a storm surge in December 1973, which had a height of the order of a couple of meters. However, observations with optical interferometers are not likely to be taking place close to where storm surges are occuring.

Another paper by Zschau which gives an idea of how complex distortions of the earth's surface can be is on alr-pressure-induced tilt in porous media. ${ }^{4}$ As an example, tilts with periods of a few days near Kiel have been found experimentally to be about $2 \times 10^{-8}$ radians per millibar at a depth of 60 meters in a bore hole. The explanation of this large an effect apparently is that atmospheric pressure changes in areas where there is a slope to the surface can affect the tilt by changing the ground water level. Zschau calculates that even larger effects could occur due to this mechanism, with tilts of up to $10^{-6}$ radians per millibar being possible at 30 meters depth for soil which is a mixture of silt and clay and has $10 \%$ surface slope 
The effect is calculated to be period-dependent because of the time necessary for water to flow through the pores in the ground.

Atmospheric pressure effects also have been observed in gravity measurements made by Warburton and Goodkind with very accurate superconducting gravimeters. 5 In addition to tidal displacements, they find a strong correlation of the residual non-tidal gravity variations with the barometric pressure. While much of this effect is due to the direct attraction of the gravimeter test mass by the atmosphere, part is calculated to be due to the displacements of the ground surface caused by the atmospheric pressure loading. For a 20 millibar localized change in atmospheric pressure considered as a surface load over a level area of radius 200 kilometers, the corresponding calculated tilt would be of the order of $10^{-8}$ radians

\section{LONG PERIOD GROUND MOTIONS}

For periods of weeks to years which might still be of interest for some astrometric applications of stellar interferometry, such as possible measurements of UT 1 and polar motion, the situation is more complicated. Very little experimental data on tilt is available, since tilt meters built previously did not have sufficient long term stability to observe long term variations with amplitudes of $10^{-7}$ to $10^{-8}$ radians Modern liquid level tilt meters with lengths of up to a kilometer are being built or planned at the University of Washington, 6 the University of California at San Diego, 7 and the LamontDoherty Geophysical Observatory: 8 However, for the present most of the information available on long term ground stability concerns strain rather than tilt.

Two observatories where carefully constructed laser strainmeters have been in operation for some time provide interesting information on ground distortions at longer periods. The first of these is the Piñon Flat Observatory operated by the University of California at San Diego. It is located between the San Andreas and the San Jacinto Fault systems in southern California. Three laser strainmeters with lengths of 732 meters and oriented in the $\mathrm{N}-\mathrm{S}, \mathrm{E}-\mathrm{W}$ and $\mathrm{N}-\mathrm{W}, \mathrm{S}-\mathrm{E}$ directions are in operation. The laser beams travel through evacuated pipes to remove the effect of 
atmospheric density variations. Descriptions of earlier work with these interferometers have been given by Berger and Wyatt ${ }^{9}$ and by Berger. 10

The main problem encountered has been with the stability of the piers. For the $\mathrm{N}-\mathrm{S}$ and $\mathrm{E}-\mathrm{W}$ instruments granite piers about 3 meters in height and 70 centimeters across were carefully installed in holes about 2 meters deep. However, tilting of the piers was found to be a serious problem and tiltmeters later were installed on the piers in order to permit correction of the laser strainmeter results. The N-W, S-E instrument has shorter piers and shows less tilt, but the overall stability of the length of this instrument appears to be considerably worse. Secular strain rates are of the order of $1 \times 10^{-7} / \mathrm{yr}$ for the $\mathrm{N}-\mathrm{S}$ and $\mathrm{E}-\mathrm{W}$ instruments. ${ }^{11}$ However, fairly rapid length changes of the order of $1 \times 10^{-7}$ are observed at times of heavy rainfall. This probably is associated with local motions of the piers, which may be a very difficult problem to overcome for tilts of the order of $10^{-8}$ radians, as well as for strain.

Another laser strainmeter has been operated by the National Bureau of Standards in a mine near Boulder, Colorado. ${ }^{12-14}$ The total 1ong-term strain change over a period of about 2 yrs was about $2 \times 10^{-7}$, with much of that change occuring during the first 6 mos when the interior of the mine was unusually wet. 15 The instrument is located about 60 meters below the ground surface, and no short-term correlation with rainfall has been observed.

The power spectrum of earth strain observations in California and Colorado has been compared by Berger and Levine ${ }^{16}$ over a range of from $10^{-8}$ to $10^{2} \mathrm{~Hz}$. The results are remarkably similar. Results obtained by Beavan and Goulty ${ }^{17}$ with a laser strainmeter operated in the Queensbury tunnel in England for a period of 74 days gives a comparable noise level at the lower frequencies, but considerably higher noise at high frequencies.

Quite a bit of information on possible ground distortions also is contained in theoretical studies. In a recent paper on thermoelastic strains, Harrison and Herbst ${ }^{18}$ discuss the effect of the interaction between surface topography and temperature variation. As an example, they take a pair of sinusoidal ridges each 6 meters high and 10 meters across. With a finite 
element calculation they find that an annual temperature range of $25^{\circ}$ at the surface can give maximum tilts on the sides of the ridges of close to $10^{-4}$ radians. While this is an extreme case, the results indicate that the effects of the interaction between thermoelastic strains and topography can be quite strong. In addition, they conclude their paper by saying: "These may, however, not be the most important meterologically-related perturbations; lateral variations in albedo and in the thermal and mechanical properties of the soil may be important. Freezing of the ground in winter may produce a stretched boundary layer somewhat similar to that produced by thermal expansion, and rainfall can be expected to produce important effects, both by modifying the thermal regime and in other ways."

Another effect of possible interest is seasonal distortions due to changes in atmospheric pressure and ground water storage. Stolz and Larden ${ }^{19}$ have discussed distortions due to seasonal atmospheric pressure changes and find that the expected displacements are near $1 \mathrm{~cm}$ in Siberia and Greenland and are slightly larger than $1 \mathrm{~cm}$ over the Antarctic. Comparable changes over more temporate land areas are expected to occur due to changes in the ground water storage on the continents with seasons. Hylckama's data, as quoted by Munk and McDonald, 20 indicate variations of 10-20 grams per centimeter squared for many parts of the world. As a rough check on the magnitude of the effect expected, an $8^{\circ}$ radius spherical cap with a uniform load of 10 grams per centimeter squared would give a displacement of the surface at the center of 0.44 centimeters. ${ }^{21}$ Seasonal effects due to sea leve 1 changes $^{22}$ caused by either atmospheric pressure changes or current changes need to be investigated, but probably are smaller.

Some additional impressions about the problem of local motions can be obtained from a manual for setting geodetic vertical control benchmarks which was prepared by the National Geodetic Survey 23 Information is given on the required depth to which a stainless steel rod should be driven under different conditions of soll character and frost penetration depth. A grease-filled plastic casing around the rod is required for all but the last meter or two of depth in order to prevent vertical motions of the surrounding ground from pulling up or pushing down on the rod. For example, even for soils with low 
expansive character, roughly 6 meters of casing is required in areas of normal climate. Other factors influencing the cholce of desirable sites for installing vertical control marks also are discussed.

To close on a more optimistic note, some types of baselines have turned out to be remarkably stable. The Nummela $864 \mathrm{~m}$ baseline near Helsinki has been measured a number of times since 1947 with an accuracy of about $1 \times 10^{-7}$, and has shown a shortening of only $0.5 \mathrm{~mm}$ in 30 years. ${ }^{24-26}$ This change may well be due to motion of the end marks. 8 baselines in other countries also have been measured to about $10^{-7}$ accuracy with the optical interference method since 1953, and future measurements on these lines may give further informatiori about baseline stabilities. Recently Elsmore and Ryle $\mathrm{e}^{27}$ reported obtaining the same results for a $3.4 \mathrm{~km}$ baseline at Cambridge University measured by radio interferometry to within $0.15 \mathrm{~mm}$ for two sets of measurements made about two years apart. Hopefully a lot more will be learned about ground and pier stability in the next few years.

\section{CONCLUSIONS}

Despite all the evidence of crustal distortions discussed above, most ground motions are not likely to be a problem for angular size or shape measurements. However, for possible astrometric measurements over periods of even a few days, care in the design of the end piers will be needed. For longer periods, it is not yet clear whether ground stabilities of the order of $10^{-8}$ can be achieved in practice.

\section{REFERENCES}

1) G. V. Latham and A.A. Nowroozi, J. Geophys. Res., 73, 3945, 1968.

2) A.J. Murphy, J. Savino, J.M.W. Rynn et al , J Geophys. Res., 77, 5042, 1972 .

3) J. Zschau, "Prediction of storm surges from marine loading tilt measured inland from the sea," Proc. 8th Int. Symp. on Earth Tides, Bonn, 1977 , in press.

4) $J$ Zschau, "Air pressure induced tilt in porous media," Proc. 8th Int Symp. on Earth Tides, Bonn, 1977, in press. 
5) R.J. Warburton and J.M. Goodkind, Geophys. J R. astr. Soc. 48, 281, 1977.

6) G.R. Huggett, L.E. Slater and G. Pavlis, Geophys. Res. Lett. $\underline{3}, 754,1976$.

7) J. Berger and F. Wyatt, private communication, 1978.

8) J. Beavan and R. Bilham, J. Geophys. Res. 82, 5699, 1977.

9). J. Berger and F. Wyatt, Proc. Conf. on Tectonic Problems of the San Andreas Fault System, R.K. Kovach and A. Nur, Eds., Geol. Sci., Stanford Univ- Pub1. Vo1. 13, p. 80, 1973.

10) J. Berger, Adv. Geophys. 16, 1, 1973.

11) J. Berger, in preparation, 1978.

12) J. Levine and J.L. Hall, J. Geophys. Res. 77, 2595, 1972.

13) J. Levine and J.C. Harrison, J. Geophys. Res. 81, 2543, 1976.

14) J. Levine, Geophys. J. R. astr. Soc. 54, 27, 1978.

15) J. Levine, private communication, 1978.

16) J. Berger and J. Levine, J. Geophys. Res. 79, 1210, 1974.

17) R.J Beavan and N.R. Goulty, Geophys. J. R. astr. Soc. 48, 293, 1977

18) J.C. Harrison and K. Herbst, Geophys. Res. Lett. 4, 535, 1977.

19) A. Stolz and D.R. Larden, J Geophys. Res., submitted.

20) W.H. Munk and G.J.F. MacDonald, The Rotation of the Earth, Cambridge Univ. Press, London, 1960.

21) W.E. Farre11, Rev. Geophys. Space Phys. 10, 761, 1972.

22) E. Lisitzin, Sea Level Changes, E1sevier Pub. Co., Amsterdam, 1974.

23) R.P. Floyd, Manual for Setting Geodetic Bench Marks, National Geodetic Survey, Rockville, MD, 1978.

24) T. Honkasalo, in Geodeettinen laitos - The Finnish Geodetic Institute 1918-1968, Pub. No. 65 of the Finnish Geodetic Institute, Helsinki, $57,1969$.

25) T. Parm, in Proc. Second Int. Symp. on Deformation Measurements by Geodetic Methods, Int. Fed. of Surveyors, Bonn, 1978.

26) See additional articles in: Proc. Int. Symp. on High Precision Geodetic Length Measurements, Int. Assoc. of Geodesy, Helsinki, 1978.

27) B. E1smore and M. Ryle, Mon. Not. R. astr Soc. 174, 411, 1976. 


\section{DISCUSSION}

M. Shao: Are microseisms narrow band?

P.L. Bender: Microseisms have a relatively narrow bandwidth, which is determined mainly by the frequency of ocean waves.

M. Shao: Can you comment on piers placed on bedrock?

P.L. Bender: Piers on bedrock certainly are desirable where possible. However, effects such as the modification of tilt or tides due to topography will still be present.

D.D. Cudaback: Can you make any general comments about the systematic effect of large scale continental topography which could be used as a guide in site selection?

P.L. Bender: It is very difficult to give an answer. Microseisms will be lower away from the coasts, as will ocean loading effects or the tides. However, other effects depend mainly on local conditions. 